\title{
A Longitudinal and Cross-Industry Study on the Stability of Financial Ratios of Malaysian Companies
}

\author{
Ben Chin-Fook Yap ${ }^{1}$, Zulkifflee Mohamad ${ }^{1} \&$ K-Rine Chong ${ }^{1}$ \\ ${ }^{1}$ Universiti Tun Abdul Razak, Malaysia \\ Correspondence: Ben Chin-Fook Yap, Universiti Tun Abdul Razak, Capital Square, Block C \& D, No. 8, Jalan \\ Munshi Abdullah, 50100 Kuala Lumpur, Malaysia. E-mail: benyap@unirazak.edu.my
}

Received: May 26, 2013

Accepted: June 24, 2013

Online Published: June 26, 2013

doi:10.5430/afr.v2n3p45

URL: http://dx.doi.org/10.5430/afr.v2n3p45

\begin{abstract}
The purpose of this study is to test whether a set of six financial ratios that have been used extensively by practitioners and researchers and found to be useful for various purposes including company financial performance evaluations are stable across three different industry sectors and whether they are stable over time. The sample comprises a total of 180 listed companies covering a period of five years from 2006 to 2010. Analysis of variance and post hoc multiple comparisons were carried out for each ratio to see whether it exhibits a stable profile across industries and over time. The findings showed that four out of the six ratios displayed no significant differences across industries, one (Current Assets Turnover) showed significant differences among all three sectors while the remaining ratio (Cash Flow to Total Assets) showed significant differences between two of the sectors. The test results also showed that all the financial ratios except for Cash Flow to Total Assets for all three industry sectors are stable over time. This finding is surprising in that the years 2008 and 2009 are periods where the financial crisis is at its height and companies' financial data are expected to be adversely affected and where the means of the ratio values in these two years are expected to be volatile and unstable compared to the period before and after the financial crisis. The analysis also showed that there are no interaction effects between sector and time. Thus, some ratios are industry specific and some ratios cannot be extrapolated over time when evaluating financial performance or forecasting future trends.
\end{abstract}

Keywords: Financial ratios, Stability of financial ratios, Analysis of variance

\section{Introduction}

Financial ratios have been extensively used over the years by both practitioners and researchers for financial performance evaluations (Lev, \& Sunder, 1979), for forecasting future trends (Gardiner, 1995), for predictions of company failures (Beaver, 1966; Altman, 1968; \& Ohlson, 1980 etc.), for explaining investment decisions and determining the capital structure of companies (Ozkan, 2001, Cleary, 1999) as well as used in studies of company performance efficiencies (Gumus, \& Celikkol, 2011; Devinney et al., 2010). In all the above, it has often been assumed that the ratio averages from companies can be used as benchmarks to measure and estimate the future trends and future performances of other companies as well as for future years. In order for the comparisons of company financial performances over a period of time, it is necessary that the benchmarks used, display stable profiles. Otherwise, the benchmarks are only relevant for the period in the analysis and they cannot be extrapolated into the future. Over a period of time, the economic and market conditions where companies operate change. In times of robust economic growth in a country, it can be expected that generally, most companies can expect to perform well and in times of an economic downturn or recession, many companies would face significant drop in sales, profitability and experience cash and other liquidity problems. Financial ratios computed during different periods of macro-economic conditions may show material fluctuations on the values of the ratios. How material and how significant the changes depend as much on the severity of the economic conditions as well as the fundamental financials of the individual companies. If ratios are to be used as variables to forecast or predict whether a company will succeed or go into financial distress and failure, ratios have to exhibit stable profiles over time.

Similarly, in order for comparisons of company financial performances of companies in different industry sectors, it is also necessary that the benchmarks used display stable profiles. Companies in different industries, even in the same country, have different operational, market and capital structures. Therefore, to use ratios that are found to be useful for one industry sector may not be valid for companies in another industry sector. Ocal et al. (2007) mentioned that industry financial ratios can be used for comparing the financial performance of a company with its competitor 
within the same industry as well as comparing the financial performance of companies in the same industry over time.

Another common perception about financial ratios is that certain ratios found to be useful in evaluating company financial performance can be used to forecast or predict the future performance of other similar companies. Past studies on company failure predictions (the Z-Score by Altman, 1968) have often claimed that the models they have built can be used to predict future company success or failure. However, there have been very few studies on the stability of financial ratios. A ratio is stable if its average ratio mean does not significantly change over the years or if the average means of the ratios from one industry are similar to the average means of the same ratio in another industry. It can also mean that we would expect that the values of ratios for a failed or non-failed company will always be smaller or larger than the values of the ratios for a non-failed or failed company in different years over the same period of time. In other words, the ratios should show consistent characteristics over the period of time under study. Otherwise, a ratio or a set of ratios that was derived as the predictor variables in a prediction model will not be very useful or accurate when used to predict company performances in the future. That ratio or set of ratios will only be useful and valid for the period when the analysis was done.

Some studies found that certain ratios are generally stable in one industry while not stable in other industry (Tan et al., 1997). Studies have also shown that certain ratios generally maintain a stable profile over time while others fluctuate significantly over the same period of time (Gombola, \& Ketz, 1983; Johnson, 1978; Tippett, \& Whittington, 1995, etc.).

The objective of this study is to test whether a set of financial ratios that have been used extensively by practitioners and researchers and found to be useful for various purposes including company financial performance evaluations are stable across three different industrial sectors and whether they are stable over a period of five years from 2006 to 2010.

\section{Review of Past Studies}

In their study on cross-industry and time-series stability of financial ratios for two industries, Gombola and Ketz (1983) found time-series stability for both the industries and only ratio stability within each industry. They also found that ratios in the retail and manufacturing industries are at their extreme in their characteristics and that companies in other industries seem to fall in-between these extreme ends. Their study was based on 871 companies over a period of 10 years and using fifty-eight financial ratios. However, Ketz et al. (1990) in analyzing seven industries concluded that the grouping of ratios is highly stable over the ten years period undertaken in the study and reasonably high stability across the industries except the retail industry.

Pinches et al. (1973) found that the composition of seven different groups of ratios is reasonably stable over the long term even when the size of these ratios changes over time. They also found that financial leverage is the most stable and capital intensiveness is the least stable. The mean averages for each of the ratios shifted upwards and some with no obvious movements over the years. They further used the differential-R factor analysis to measure the positional change between the two time periods 1951 and 1969 and found that there is time series stability during that period studied.

Tan et al. (1997), in their study on the stability of financial ratios calculated the means and the standard deviations to obtain an initial overall view. Using Anova, they found that there were significant variations in the ratios values over time and across industry. The main effects of time and industry and the interaction effect of time were tested. As the Anova results showed that there were significant differences over time and across industry, the Duncan multiple range tests were also conducted to show where the significant variations occur. According to them, the basic assumption is that industry averages computed can be used to benchmark similar companies in the same industry on their financial performance and also over a period of time. However, they stated that if financial ratios are not stable over time and when these ratios are used to assess company performance, this inter-relationship will only be valid for the sample period and cannot be extrapolated into the future. When ratios are not stable over time or across industries, the predictive powers of the ratios can severely be limited and poor decisions may result when these ratios are used for forecasts and predictions.

Wood and Piesse (1987) in their study of the information value of Multiple Discriminant Analysis based financial indicators said that though robust and reliable ex-post classification is possible, the question that still arises is whether such classificatory accuracy demonstrates that the information are of value in decision situations of forecast accuracy, credit and loan extensions. They found that the evidence for information value is inconclusive and they suggest that these results occur due to the values of certain independent variables that differ significantly between the forecast period and the estimation period. They attributed these differences to phases of the business cycle, changes in the market environment, and changes in corporate strategy, technological changes etc. All these imply that 
financial ratios are not stable over time. Here again, in this study, stationarity of the variables is a main problem and if this issue is not addressed sufficiently, forecast accuracy based on forecasting models may not be accurate.

In their study on ratio stability, Dambolena and Khoury (1980) used (1) the standard deviation of the financial ratios over the past few years, (2) their standard error of estimate, and (3) their coefficient of variation. They found that when the stability of ratios is taken into account when they study failure predictions, they can obtain a better discriminant function.

Betts and Belhoul (1987) also used the variation in the ratios and came to similar conclusions as Damnbolena and Khoury (1980) in that the use of the variation in financial ratios to measure the stability of the ratios and found that improvements in ex post classification results relative to models without measures of variation. They further found that the financial stability concept does not reduce the role played by financial ratio analysis in forecasting company failure, but is merely complementary to it.

Dambolena and Khoury (1980), presented an alternative model on company failure using financial ratios and discriminant analysis where they used ratio stability over time as an essential characteristic in that model. Their analysis found that there is a substantial degree of instability as measured by the standard deviation of the financial ratios over a specified period of time, the standard of error of estimate and the coefficient of variation among the companies that are in distress and those that are not. They claimed that by including the stability of ratios in their analysis, the discriminant function derived can better predict company failures. They analyzed 46 companies in the retail and manufacturing sector using 19 financial ratios.

Johnson (1978) found that when financial ratios with similar characteristics are grouped, the ratios are relatively stable across the retail and manufacturing industry. He utilized 465 manufacturing and retail companies with 61 financial ratios. The average value for each of the 61 ratios were calculated and univariate and multivariate t-tests were used to find out whether there are significant cross-sectional differences among these averages. When significant differences were found, the Hotelling $\mathrm{T}^{2}$ statistic would be used to confirm the existence of the cross-sectional differences. Four component groups were identified after the factor analysis. To assess the cross-sectional stability of the component groups, the groups were further analyzed by visual comparison, pair-wise comparison of factors using congruency coefficients and canonical analysis of the component groups with all factors compared simultaneous time periods and across the retail and manufacturing industries.

Platt and Platt (1990), in their study on stable predictive variables for bankruptcy models, said that due to the instability of variables over time and across industries, using industry relative ratios are more accurate as forecasting variables. According to them, industry relative ratios hold several advantages over unadjusted or raw ratios when used to predict corporate failure. They said that within a period of time, industry-relative ratios measure all companies on the same scale, regardless of industry and that across time periods; industry-relative ratios should be more stable, thus yielding more accurate forecasts of the financial position of companies. They defined an industry-relative ratio as a ratio of a firm's financial ratio relative to the mean value for that ratio in the firm's industry at a point. The results of their study indicated that models constructed with industry-relative ratios gave greater classification accuracy and that the classification rates were stable over time.

According to Engle and Granger (1987), the statistical inferences from regression techniques will be invalid and the statistical relationship derived, may be spurious if the variables used are not stable or stationary. Studies by Pinches et al. (1973) and Gombola and Ketz (1983) showed that ratios are stable over time while studies by Tippett and Whittington (1995) and Tan et al. (1997) showed though ratios are generally stable over time but some ratios showed significant differences over time.

\section{Methodology}

\subsection{Sample Size}

In this study, financial statements from the annual reports of public companies listed in the Bursa Saham Malaysia (the Malaysian Stock Exchange) will be classified into three sectors, namely:

(i) the consumer sector,

(ii) the industrial products sector, and

(iii) the trading and services sector.

The companies would be randomly selected and analyzed over a period of five years from 2006 to 2010 . Two of the industry sectors are involved in manufacturing activities, one manufacturing industrial products while the other manufactures consumer products. The third sector is involved in the trading of goods and the provision of services. The sample period selected, covers the period just before the start and the beginning of the recovery of the global financial crisis of 2007/2008. The number of companies selected for each sector is as shown in Table 1 below: 
Table 1. Profile of companies in the analysis

\begin{tabular}{lll}
\hline Sector & Principal activities & No of Companies \\
\hline Consumer Products & Manufacturing & 70 \\
Industrial Products & Manufacturing & 70 \\
Trading \&Services & Trading \& services & 40 \\
Total & & 180
\end{tabular}

\subsection{Variables Selection}

Six financial ratios are selected for this study. These ratios have been used and found to be effective in various studies including the studies by Altman (1968), Deakin (1972), Pinches (1973), Tan et al. (1979) and Hossare and Rahman (2005). Two of the ratios measure a company's leverage and solvency while one ratio measures the companies' profitability, one ratio measures the efficiency of its utilization of its assets and two ratios measure the companies' cash and liquidity positions. The six ratios are shown in Table 2 below:

Table 2. Financial Ratios

\begin{tabular}{lll}
\hline Ratios & Codes & Represents \\
\hline Earnings before Interest and Tax & EBITTA & Profitability \\
Current Assets Turnover & CAT & Operating Asset Efficiency \\
Cash Flow to Total Assets & CFTA & Short-term Liquidity \\
Cash to Current Liabilities & CCL & Cash Position \\
Total Debts to Total Assets & TDTA & Solvency \\
Total Debts to Shareholders: Funds & TDSF & Solvency \\
\hline
\end{tabular}

\section{Methodology}

The financial ratios are assessed as to whether they are stable over a period of time and also across different industry sectors. As there are two independent variables, the SPSS General Linear Models, Two Way Anova would be used to gain an understanding of how the two independent categorical variables (Sector and Time) influence a single continuous dependent variable which is the values of all the six financial ratios for the three sectors over the period of five years. The six financial ratios for all the 180 companies in the three sectors are used in this analysis. The ANOVA results would indicate whether financial ratios were stable (i.e. whether the means were significantly different) over time and across industry. It is similar to the t-test where only two groups are tested. Post hoc comparisons will be carried out between the variables. For these comparisons, the commonly used Tukey test will be utilized.

According to Platt and Platt (1990), a stable variable is defined as one in which the mean does not change across the estimation and forecast time periods and is one that shows the least change in the mean value from between the two periods. A stable ratio can be reflected in equation:

$$
\begin{gathered}
(\mathrm{X},, \mathrm{f})=\text { Mean }(X, . .)(2) \\
E=\text { the estimation period }
\end{gathered}
$$

where: $X=a$ financial ratio

$i=\mathrm{r}$ a t i o $1, \ldots n \quad F=$ the forecast period.

The results of the tests would show whether there are significant differences between the means of the three industrial sectors and also whether there are significant differences in the means across time.

\section{Findings and Discussions}

Firstly, Levene's Test of the equality of error variances would be examined. The alpha value is set at 0.05 and if the significant level is above this level, then there is homogeneity of variances and if this value is below 0.05 , then it can be concluded that the variance across the sectors and across time were significantly different meaning that the variances are unequal. The results of Levene's test are tabulated in Table 3 below. Only two ratios, EBITTA and TDTA showed that there is homogeneity of variance. The other four ratios have p-values of $<0.05$ indicating that their sample means are different and outliers may be present. To find out which samples are different, the Tukey post hoc test will indicate where the differences are.

Table 3. Levene's Test of Equality of Error Variances

\begin{tabular}{lll}
\hline Ratios & F & Significance \\
\hline EBITTA & 1.335 & .180 \\
CAT & 2.777 & .000 \\
CFTA & 2.049 & .012 \\
TDTA & 1.537 & .092 \\
CCL & 2.141 & .008 \\
TDSF & 2.511 & .002 \\
\hline
\end{tabular}


Table 4 below shows the results of the Tukey tests of whether the ratio means of the three different sectors are significantly different from each other. If the significant level is 0.05 and below (highlighted in bold), then there is a significant difference between the sectors and if the significant level is over 0.05 , then there is no significant difference between the sectors. The results showed that for EBITTA, TDTA, CCL and TDSF, there are no significant differences between all three sectors while for CAT, there are significant differences between Consumers, Trading \& Services and Industrial Products while there are significant differences between the Consumer products and the Trading \& Services sector for Cash Flow to Total Assets.

Table 4. Multiple Comparisons between Sectors

\begin{tabular}{|c|c|c|c|}
\hline Ratios & Sector & Sectors & (p-value). \\
\hline \multirow[t]{6}{*}{ EBITTA } & Consumer & Industrial Products & .136 \\
\hline & & Trading \& Services & .275 \\
\hline & Industrial Products & Consumer & .136 \\
\hline & & Trading \& Services & .995 \\
\hline & Trading \& Services & Consumer & .275 \\
\hline & & Industrial Products & .995 \\
\hline \multirow[t]{6}{*}{ CAT } & Consumer & Industrial Products & .000 \\
\hline & & Trading \& Services & .000 \\
\hline & Industrial Products & Consumer & .000 \\
\hline & & Trading \& Services & .217 \\
\hline & Trading \& Services & Consumer & .000 \\
\hline & & Industrial Products & .217 \\
\hline \multirow[t]{6}{*}{ CFTA } & Consumer & Industrial Products & .016 \\
\hline & & Trading \& Services & .000 \\
\hline & Industrial Products & Consumer & 016 \\
\hline & & Trading \& Services & 023 \\
\hline & Trading \& Services & Consumer & 000 \\
\hline & & Industrial Products & .023 \\
\hline \multirow[t]{6}{*}{ TDTA } & Consumer & Industrial Products & .074 \\
\hline & & Trading \& Services & .976 \\
\hline & Industrial Products & Consumer & .074 \\
\hline & & Trading \& Services & .096 \\
\hline & Trading \& Services & Consumer & .976 \\
\hline & & Industrial Products & .096 \\
\hline \multirow[t]{6}{*}{$\mathrm{CCL}$} & Consumer & Industrial Products & .764 \\
\hline & & Trading \& Services & .465 \\
\hline & Industrial Products & Consumer & .764 \\
\hline & & Trading \& Services & .828 \\
\hline & Trading \& Services & Consumer & .465 \\
\hline & & Industrial Products & .828 \\
\hline \multirow[t]{6}{*}{ TDSF } & Consumer & Industrial Products & .292 \\
\hline & & Trading \& Services & .516 \\
\hline & Industrial Products & Consumer & .292 \\
\hline & & Trading \& Services & .982 \\
\hline & Trading \& Services & Consumer & 516 \\
\hline & & Industrial Products & .982 \\
\hline
\end{tabular}

Table 5 below shows the Tukey post hoc tests of whether the means for the five years are significantly different from each other. If the significant level is 0.05 and below, then there is a significant difference in the means in the five years time period and if the significant level is over 0.05 , then there is no significant difference in the means in the five years time period. The test results showed that the means of the ratios of companies in each industry are not significantly different over time. In other words, the financial ratios for all three industry sectors are stable over time 
and that the ratios means do not significantly change significantly over the five year period in the study. The results showed that for all the ratios, except CFTA, and for all the years there are no significant differences in the means of the ratios between the different years. For CFTA, the ratio means are significantly different between Year 2 and year 3 , between year 2 and year 4 and between year 2 and year 5 and marginally different between year 2 and year 1 ( $p$-value $=0.051)$. Overall it can be seen that financial ratios are generally stable over time.

Table 5. Multiple Comparisons Over Time

\begin{tabular}{llllllll}
\hline & & EBITTA & CAT & CFTA & TDTA & CCL & TDSF \\
\hline Years & Years & P-value & P-value & P-value & P-value & P-value & P-value \\
1.00 & 2.00 & .891 & 1.000 & .051 & .961 & .998 & .990 \\
& 3.00 & .662 & .454 & .522 & .309 & .313 & .784 \\
& 4.00 & .994 & .881 & .867 & .994 & .733 & .987 \\
& 5.00 & .998 & .998 & .533 & .998 & .445 & .970 \\
2.00 & 1.00 & .891 & 1.000 & .051 & .961 & .998 & .990 \\
& 3.00 & .158 & .453 & .000 & .072 & .505 & .488 \\
& 4.00 & .987 & .881 & .002 & .999 & .892 & 1.000 \\
& 5.00 & .733 & .998 & .000 & .853 & .652 & 1.000 \\
& 1.00 & .662 & .454 & .522 & .309 & .313 & .784 \\
& 2.00 & .158 & .453 & .000 & .072 & .505 & .488 \\
& 4.00 & .400 & .950 & .977 & .135 & .961 & .471 \\
& 5.00 & .841 & .285 & 1.000 & .504 & .999 & .392 \\
& 1.00 & .994 & .881 & .867 & .994 & .733 & .987 \\
& 2.00 & .987 & .881 & .002 & .999 & .892 & 1.000 \\
& 3.00 & .400 & .950 & .977 & .135 & .961 & .471 \\
& 5.00 & .951 & .732 & .979 & .946 & .991 & 1.000 \\
& 1.00 & .998 & .998 & .533 & .998 & .445 & .970 \\
& 2.00 & .733 & .998 & .000 & .853 & .652 & 1.000 \\
& 3.00 & .841 & .285 & 1.000 & .504 & .999 & .392 \\
& 4.00 & .951 & .732 & .979 & .946 & .991 & 1.000 \\
\hline
\end{tabular}

Table 6. Tests of Between-Subjects Effects

\begin{tabular}{llllll}
\hline EBITTA & Type III Sum of Squares & df & Mean Square & F & Sig. \\
Sector & .029 & 2 & .015 & 2.144 & .118 \\
Year & .065 & 4 & .016 & 2.361 & .052 \\
Sector * Year & .074 & 8 & .009 & 1.353 & .214 \\
\hline CAT & & & & & \\
Sector & 46.999 & 2 & 23.500 & 29.898 &. $\mathbf{0 0 0}$ \\
Year & 4.602 & 4 & 1.151 & 1.464 & .211 \\
Sector * Year & 2.757 & 8 & .345 & .438 & .898 \\
\hline CFTA & & & & & \\
Sector & .128 & 2 & .064 & 12.801 & $\mathbf{. 0 0 0}$ \\
Year & .107 & 4 & .027 & 5.357 &. $\mathbf{0 0 0}$ \\
Sector * Year & .054 & 8 & .007 & 1.357 & .212 \\
\hline TDTA & & & & & \\
Sector & .190 & 2 & .095 & 3.183 & $\mathbf{. 0 4 2}$ \\
Year & .403 & 4 & .101 & 3.379 &. $\mathbf{0 0 9}$ \\
Sector * Year & .387 & 8 & .048 & 1.624 & .114 \\
\hline CCL & & & & & \\
Sector & 1.029 & 2 & .514 & .721 & .487 \\
Year & 4.353 & 4 & 1.088 & 1.525 & .193 \\
Sector * Year & 3.492 & 8 & .437 & .612 & .768 \\
\hline TDSF & & & & & \\
Sector & 1.289 & 2 & .645 & 1.251 & .287 \\
Year & 2.845 & 4 & .711 & 1.381 & .239 \\
Sector * Year & 5.780 & 8 & .722 & 1.402 & .191 \\
\hline
\end{tabular}


Table 6 above, displays the results of the analysis of the main effects of Sectors and main effects of Time and the interaction effects of Sector and Time (Sector*Year). The main effect is the effect of one of the independent variable on the dependent variable ignoring the effect of the other independent variable. Particular attention is paid to the interaction effect of the two independent variables. If there are any significant effects, the p-value would be less than 0.05 and if the p-value is greater than 0.05 , then there are no significant effects, whether it is the main or the interaction effect.

The analysis of the tests showed that there are no interaction effects between sector and time. The table also showed that there are significant main effects between Sector and the dependent variables CAT ( $\mathrm{p}$-value $=0.000$ ), CFTA $(p$-value $=0.000)$, TDTA ( $p$-value $=0.042)$ and LTDTA $(p$-value $=0.000)$ and significant main effects between Time and the dependent variables CFTA ( $\mathrm{p}$-value $=0.000)$ and TDTA ( $\mathrm{p}$-value $=0.009$ ).

\section{Conclusions}

The analysis of stability of ratios across industries showed that four ratios namely, Earnings before Interest and Tax (EBITTA), Total Debts to Total Assets (TDTA), Cash to Current Liabilities (CCL) and Total Debts to Shareholders Funds (TDSF) out of the six ratios showed no significant differences across the three industrial sectors. The only ratio that showed significant difference across the three sectors is Current Assets Turnover (CAT). Cash Flow to Total Assets (CFTA) showed significant differences between Consumer and Industrial Products but no difference with the Trading and services sector.

It is found that financial ratios are generally stable over time. The results showed that five of the six ratios used in the tests showed stability over the five year period where the mean values do not significantly change from one year to another. Even for CFTA, where there are some differences over the years, the changes are for some specific years and not all the years. This finding is surprising in that the years 2008 and 2009 are periods where the financial crisis is at its height and companies' financial data are expected to be adversely affected and where the means of the ratio values in these two years are expected to be volatile and unstable compared to the period before and after the 2007/2008 financial crisis that started in the United States.

The finding that is of importance to note is that there are no significant interaction effects of industry and time (sector*time). For those ratios that display significant differences in different industries they are not stable across industries and caution should be exercised in using those ratio averages of one industry to apply to other industries.

The results of this study will enhance the knowledge towards a better understanding of whether financial ratios possess a stable profile across different industries and over time. The study will add to the current literature especially when past studies have shown differing degree of stability between industries and stability over time. Furthermore, it is also reasonable to assume that the explanatory power of financial ratios is not similar when applied in different countries where the operating and market conditions and the legal and statutory requirements may be different. The value of a ratio that was found to be acceptable in a country but when applied in another country may not be viewed as within the acceptable range.

\section{Limitations of the Study and Future Studies}

This study covers only public listed companies listed in Bursa Malaysia, formerly known as the Kuala Lumpur Stock Exchange. Companies selected for analysis would exclude private companies and nonindustrial companies like public utilities, transportation companies and financial institutions as their corporate structures and the financial and other regulations governing accounting and reporting standards may be different. Only 180 companies were selected covering a five year period from 2006 to 2010 and come from the consumer product sector, the industrial product sector and the trading and services sector. Future studies could not only expand on the number of companies to be studied in the three sectors but in other sectors to see whether similar conclusions can be made.

\section{References}

Altman, E.I. (1968). Financial ratios, discriminant analysis and the prediction of corporate bankruptcy. Journal of Finance, 23(4), 589-609. http://dx.doi.org/10.1111/j.1540-6261.1968.tb00843.x

Beaver, W.H. (1966). Financial ratios as predictors of failure. Journal of Account Research, 4, 71-111. http://dx.doi.org/10.2307/2490171

Betts, J. \& Belhoul, D. (1987). The effectiveness of incorporating stability measures in company failure models. Journal of Business Finance \& Accounting, $14(3), \quad 323-334$. http://dx.doi.org/10.1111/j.1468-5957.1987.tb00098.x 
Cleary, S. (1999). The relationship between firm investment and financial status. Journal of Finance, 54(2), 673-92. http://dx.doi.org/10.1111/0022-1082.00121

Dambolena, I.G. \& Khoury, S.J. (1980). Ratio stability and corporate failure. The Journal of Finance, 35(4), 1017-1026. http://dx.doi.org/10.1111/j.1540-6261.1980.tb03517.x

Deakin, E.B. (1976). Distribution of financial accounting ratios: Some empirical evidence. The Accounting Review, 51, 90-96.

Devinney, T.M., Yip, G.S., \& Johnson, G. (2010). Using frontier analysis to evaluate company performance. British Journal of Management, 21, 921-938. http://dx.doi.org/10.1111/j.1467-8551.2009.00650.x

Engle, R. \& Granger, C. (1987). Co-integration and error correction: Representation, estimation and testing. Econometrica, 55, 251-76. http://dx.doi.org/10.2307/1913236

Gombola, M. J. \& Ketz, J. E. (1983). A note on cash flow and classification patterns of financial ratios. The Accounting Review, 42(1), 105-114.

Gardiner, M. (1995). Financial ratios definitions reviewed. Management Accounting 73(8), 32.

Gümüs, Y. \& Celikkol, H. (2011). Data envelopment analysis: An augmented method for the analysis of firm performance. International Research Journal of Finance and Economics, 79, 137-142.

Hossari, G \& Rahman, S. (2005). A comprehensive formal ranking of the popularity of financial ratios in multivariate modeling of corporate collapse. Journal of American Academy of Business, 6(1), 321-327.

Johnson, W.B. (1979). The cross sectional stability of financial patterns. Journal of Business Finance and Accounting, 5, 207-214. http://dx.doi.org/10.1111/j.1468-5957.1978.tb00183.x

Ketz, J. E., Doogar, R.K., \& Jensen, D.E. (1990). A cross-industry analysis of financial ratios: Comparabilities and corporate performance. Connecticut: Quorum Books.

Lev, B. \& Sunder, S. (1979). Methodological issues in the use of financial ratios. Journal of Accounting and Economics, 187-210. http://dx.doi.org/10.1016/0165-4101(79)90007-7

Ocal, M.E., E.L., Erdis, E., \& Vera, G. (2007). Industry financial ratios-application of factor analysis in Turkish construction industry. Building and Environment, 42, 385-392. http://dx.doi.org/10.1016/j.buildenv.2005.07.023

Ohlson, J. A. (1980). Financial ratios and the probabilistic prediction of bankruptcy. Journal of Accounting Research, Spring, 109-131. http://dx.doi.org/10.2307/2490395 http://dx.doi.org/10.2307/2490395

Ozkan, A. (2001). Determinants of capital structure and adjustment to long run target evidence from UK company panel data. Journal of Business Finance \& Accounting, 28(1\&2), 175-98. http://dx.doi.org/10.1111/1468-5957.00370

Pinches, G.E., Mingo, K.A., \& Caruthers, J. K. (1973). The stability of financial patterns in industrial organizations. Journal of Finance, 28(3), 389-396. http://dx.doi.org/10.1111/j.1540-6261.1973.tb01782.x

Platt, J.D. \& Platt, M.B. (1990). Development of a class of stable predictive variables: The case of bankruptcy prediction. Journal of Business, Finance and Accounting, 17(1), 31-51. http://dx.doi.org/10.1111/j.1468-5957.1990.tb00548.x

Tan, P.M.S., Koh, H.C., \& Low, L.C. (1997). Stability of financial ratios: A study of listed companies in Singapore. Asian Review of Accounting, 5(1), 9-39. http://dx.doi.org/10.1108/eb060680

Tippett, M. \& Whittington, G. (1995). An empirical evaluation of an induced theory of financial ratios. Accounting and Business Research, 25(9), 208-18. http://dx.doi.org/10.1080/00014788.1995.9729943

Wood, D. \& Piesse, J. (1987). The information value of MDA based financial indicators. Journal of Finance and Accounting, 14(1), 27-38. 